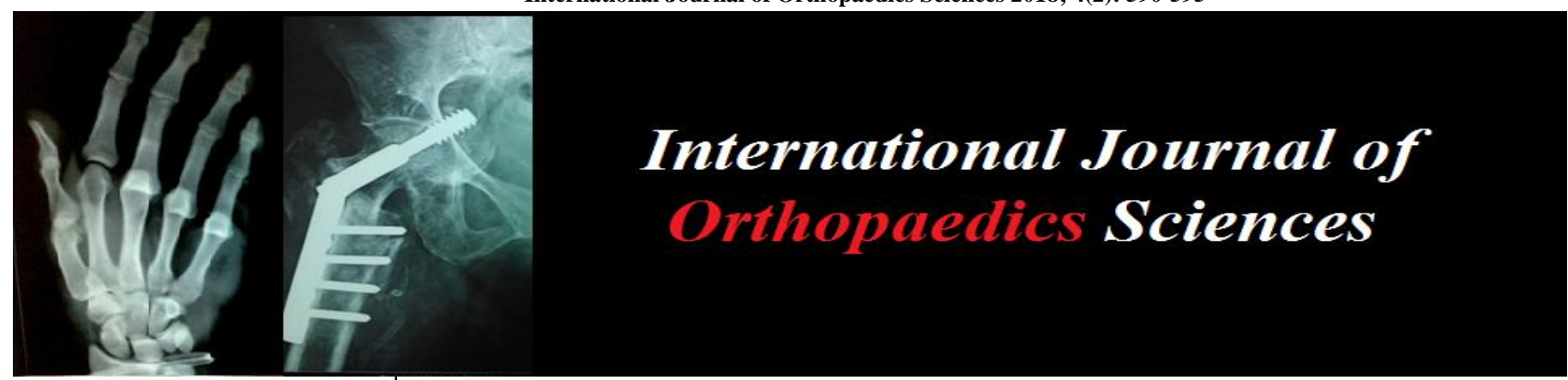

ISSN: $2395-1958$

IJOS 2018; 4(2): 590-595

(C) 2018 IJOS

www.orthopaper.com

Received: 18-02-2018

Accepted: 19-03-2018

Dr. TC Premkumar

M.S. Ortho, D. Ortho,

Senior Assistant Professor,

Department of Orthopaedics and Traumatology, Madurai Medical

College, Madurai,

Tamil Nadu, India

Dr. Pathiarasakumar

M.S. Ortho, Assistant Professor,

Department of Orthopaedics and

Traumatology, Madurai Medical

College, Madurai, Tamil Nadu,

India
Correspondence

Dr. TC Premkumar

M.S. Ortho, D. Ortho,

Senior Assistant Professor,

Department Of Orthopaedics

and Traumatology, Madurai

Medical College, Madurai,

Tamil Nadu, India

\section{A study on functional outcome following surgical fixation for subaxial cervical spine injuries}

\section{Dr. TC Premkumar and Dr. Pathiarasakumar}

DOI: https://doi.org/10.22271/ortho.2018.v4.i2i.88

\section{Abstract}

Background: Cervical instability due to trauma is usually from level c3 to c7 (i.e sub axial). Neurological deficit are common i.e root compression and cord compression with subluxation and dislocation. Unstable cervical spine injuries with or without neurological deficit require open reduction. Stabilization is done by using various implants and bone grafting. Implants provide immediate stability, whereas bone grafts provide long term stability by achieving intervertebral fusion. Hence to relive from the primary impact, persistent compression and alignment of stable anatomy of cervical spine, early surgical intervention is necessary to relieve persistent compression and stabilization of subaxial cervical spine injuries.

Aim of the study: To study the functional outcome following surgical fixation for subaxial cervical spine injuries involving patients who all are admitted with subaxial cervical spine injuries \& amenable to intervention in our department of orthopaedics \& traumatology, govt rajaji hospital, madurai from September 2011 to September 2015

Results: all the cases are male with most of the patients are in the age group of 41-50 years, Fall from height is the most common of injury followed by road traffic accident, C5-C6 \# dislocation is most common spinal injury pattern. Incomplete neurological deficit are more in this study. Most of the cases are flexion distraction type of violence. Most of the cases presented with in one week of injury. Only 4 cases of 40 cases operated by global fusion, both of them are presented late and found to have locked facets. 4 out of 6 cases are expired from complete neurological deficit. Mobilisation of neck started after 6 weeks. Totally 6 cases were expired. Two cases was due to acute respiratory distress syndrome. One case due to aspiration pneumonia is. Four patients developed bed sores in which one case developed bed sore preoperatively and other postoperative lay. One patient who had grade 6 sacral sore underwent flap cover with the help of plastic surgeon intervention. Other 6 patients managed conservatively.

Conclusion: The ultimate goal of surgical intervention for subaxial cervical spine injuries is stabilization of spine, restoration of spinal anatomy, decompression of neural elements, thereby promoting the neurological recovery and early facilitation of rehabilitation. In our study, we achieved a good functional outcome following surgical intervention. To conclude that early surgical stabilization of subaxial cervical spine injuries has good functional outcome, provided detailed clinical and radiological assessment, proper preoperative planning, selection of surgical approaches, precision in surgical techniques and early rehabilitation program are needed in achieving good results and minimising complications.

Keywords: Subaxial spine injury, cervical spine fixation

\section{Introduction}

Cervical spine injuries are one of the common causes of morbidity \& mortality following trauma. $6 \%$ of trauma patients have spine injuries of which $>50 \%$ is contributed by cervical spine injury. Jefferson found that injuries to the cervical spine involve two particular areas c1c-c2, C5-C7. Meyer identified c2 \& c5 as two most common level of cervical injury. Injuries of the cervical spine produce neurological deficit in approximately $40 \%$ of patients. Approximately $10 \%$ of traumatic cord injuries have no obvious radiographic evidence.

Early recognition, immobilization, preservation of spinal cord function, and stabilization are the initial management of patients with cervical spine injuries. Cervical instability due to trauma is usually from level c3 to c7 (i.e sub axial). Neurological deficit are common i.e root compression and cord compression with subluxation and dislocation. Unstable cervical spine 
injuries with or without neurological deficit require open reduction . Stabilization is done by using various implants and bone grafting. Implants provide immediate stability, whereas bone grafts provide long term stability by achieving intervertebral fusion.

There is a debate in literature regarding the approach to stabilization of these fractures, particularly with regard to injuries with disruption of both the anterior and posterior column. The different approaches tht can be used are anterior, posterior, or combined approaches. Halo vests have also been advocated for treatment of these fractures.

Four characteristic mechanisms of primary injury: 1. impact plus persistent compression. 2. Impact alone with transient compression. 3. Distraction and 4. Laceration and transection. The first and most common mechanism involves impact plus persistent compression. This is evident in burst fractures with retropulsed bone fragments compressing the cord, fracture dislocation and acute disruptions. The second mechanism involves impact alone with transient compression as observed with hyperextension injuries in individuals with underlying degenerative cervical spine disease. Distraction, forcible stretching of spinal column in the axial plane, provides a third mechanism and becomes apparent when distractional forces resulting from flexion, extension, rotation or dislocation produce shearing or stretching of the spinal cord and its blood supply. This type of injury may underlie SCI without radiological abnormality, especially in children where cartilaginous vertebral bodies, underdeveloped musculature and ligament laxity are predisposing factors. This type of injury may also be a causative factor in sci without radiologic evidence of trauma, which is a syndrome most common in adults with underlying degenerative spine disease. Laceration and transaction comprise the final primary mechanism of injury. Laceration of the spinal cord may result from missile injury, sharp bone fragment dislocation, or severe distraction. Further transport of the patients and persistent movements of neck will results in secondary impact and compression. Cervical spine instability also contributes the additional factor for secondary impact and compression. Hence to relive from the primary impact, persistent compression and alignment of stable anatomy of cervical spine, early surgical intervention is necessary to relieve persistent compression and stabilization of sub axial cervical spine injuries. We have done the procedure of decompression and fusion with cervical $\mathrm{H}$ plate for the sub axial cervical spine injuries.

\footnotetext{
Implants and Instruments

1. cervical H-plate

2. $3.5 \mathrm{~mm}$ cortical screws

3. Casper pins

4. Casper distractor

5. Stainless steel wire

6. Osteotome and mallet

7. Nibbler

8. Graft punch(6)
}

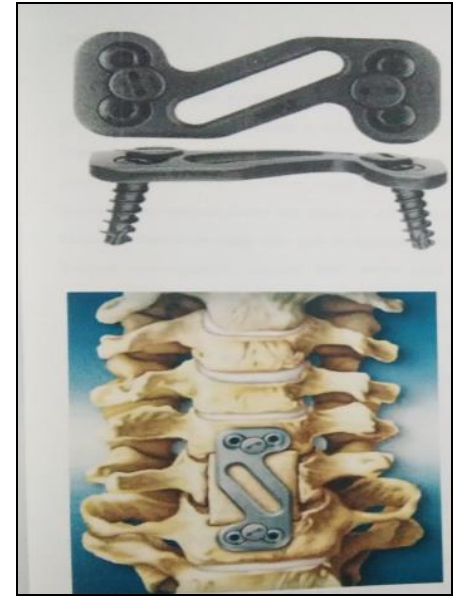

\section{Materials and methods Study design}

It is prospective study involving 34 patients who are all admitted with sub axial cervical spine injuries and amenable to intervention in our department of Orthopaedics and traumatology, Govt Rajaji hospital Madurai.

\section{Inclusion Criteria}

1. 18-65 years of both sex

2. Cervical spine injury with instablity involving C3 cervical level to $\mathrm{C} 7$ cervical spine level

3. Traumatic disc prolapse impinging the cord involving $\mathrm{C} 3$ to $\mathrm{C} 7$ cervical spine level

4. All patients with cord damage whether complete or incomplete cord lesions.

\section{Exclusion Criteria}

1. Medical co morbidities eg: malignancy, severe liver disease, organic brain disease

2. Multiple injuries that influence the function

3. Thoracolumbar spinal injuries

4. Previous cervical spine injuries

\section{Initial Management}

- Management of airway breathing circulation

- Cervical collar immobilisation

- Fluid and electrolyte management

- Assessment of neurological status by ASIA motor score

- Methyl prednisolone succinate if injury is $<8 \mathrm{hrs}$. old dose $30 \mathrm{mg} / \mathrm{kg}$ in first 15 minutes followed by $5.4 \mathrm{mg} / \mathrm{kg} / \mathrm{hr}$ I.V. infusion for next $23 \mathrm{hrs}$

- $\quad$ Skull tong traction if needed

- After stabilization of patient appropriate x rays ct scan mri was taken

- Cervical injuries were classified by using standard classification system i.e Allen fergueseon classification

- Patient were assessed and surgical procedure planned.

\section{Procedure}

Anaesthesia-general Anaesthesia

Position-supine position

Incision-transverse incisions or oblique 


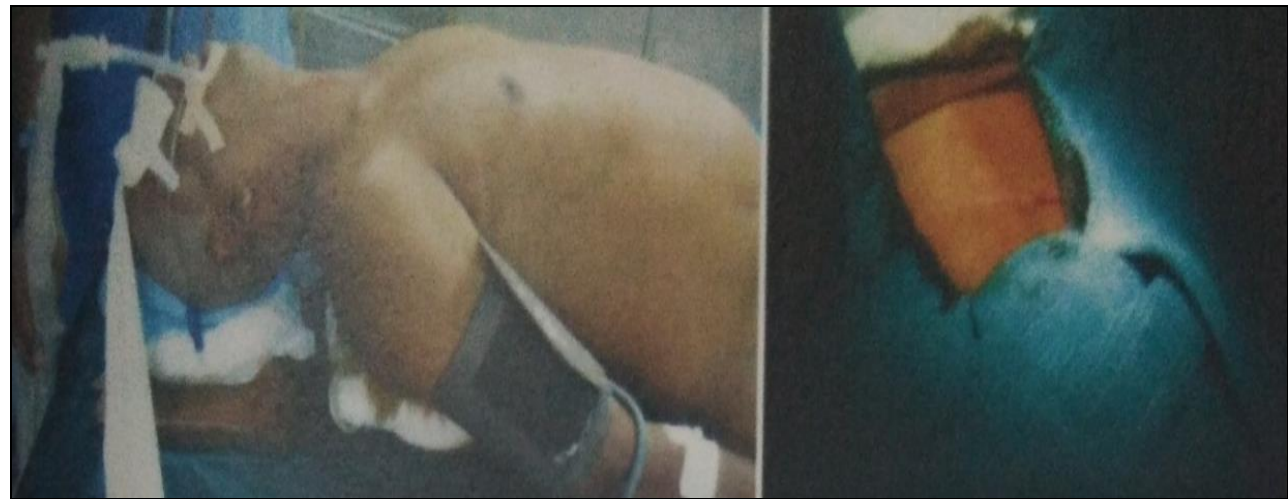

Anterior southwick and Robinson approach from right side sand bag placed under the inter scapular ipsilateral iliac regions. Both shoulders were tucked down towards the foot end of the table. This positioned ensures hyperextension thereby better visualization of the cervical spine intraoperatively .palpation of thyroid cricoid cartilage correspond to $\mathrm{C} 3, \mathrm{C} 4-\mathrm{C} 5, \mathrm{C} 6$ level respectively. a standard transverse or oblique incision was made after incising the platysma anterior border of sternocledomastoid muscle was identified. Superficial layer of deep cervical fascia was incised, carotid pulsations were palpated and scum along with carotid shesth was retracted laterally while travhea, oesophagus and thyroid were retracted medially. Deep layers of deep cervical fascia overlaying longi colli muscles were divided bluntly. Longus colli muscles were reflected sub periostealy.

A thin needle bent at 90 degree was placed in appropriate disc space and lateral radiograph was taken to verify the exact level. Anterior longitudinal ligament and annulus over disc were incised and disc taken out end plates of adjacent bodies were removed and space for graft was prepared. Spaces were packed with gel foam and wound was covered with a clean sponge. For corpectomy the body of vertebrae excluding lateral corticosteroids was removed.
A tricortical graft harvested from iliac crest equal to measured dimensions and was fashioned into a wedge to maintain cervical lordosis. Then the graft is placed either corpectomy or discectomy space. A lateral radiograph was taken to check position of graft. The anterior cortex was drilled by $2.5 \mathrm{~mm}$ bit and appropriate size cervical $\mathrm{H}$ plate was placed and screws of 14-18 mm were used and directed towards midline.

Position of screw was checked with $\mathrm{C}$ arm and then diagonally, opposite locking screw was then placed. Position of screws and plate was checked with $\mathrm{C}$ arm. After ensuring proper haemostasis, platysma, subcutaneous tissue and skin were closed in layers without drain and a cervical collar was applied and patient was extubated.

\section{Posterior Interspinous Wiring}

Wiring techniques offer the advantages of ease of application and safety. In addition they may be used to enhance other posterior fixation techniques. A hole is made on each side of the spinous process at its base and a towel clamp is used to connect the holes. A $1.2 \mathrm{~mm}$ wire is passed through the hole, brought around the spinous process of the lower level and tightened. After decorticating of the arthrodesis segment bone graft is added and the wound is closed over a suction drain.
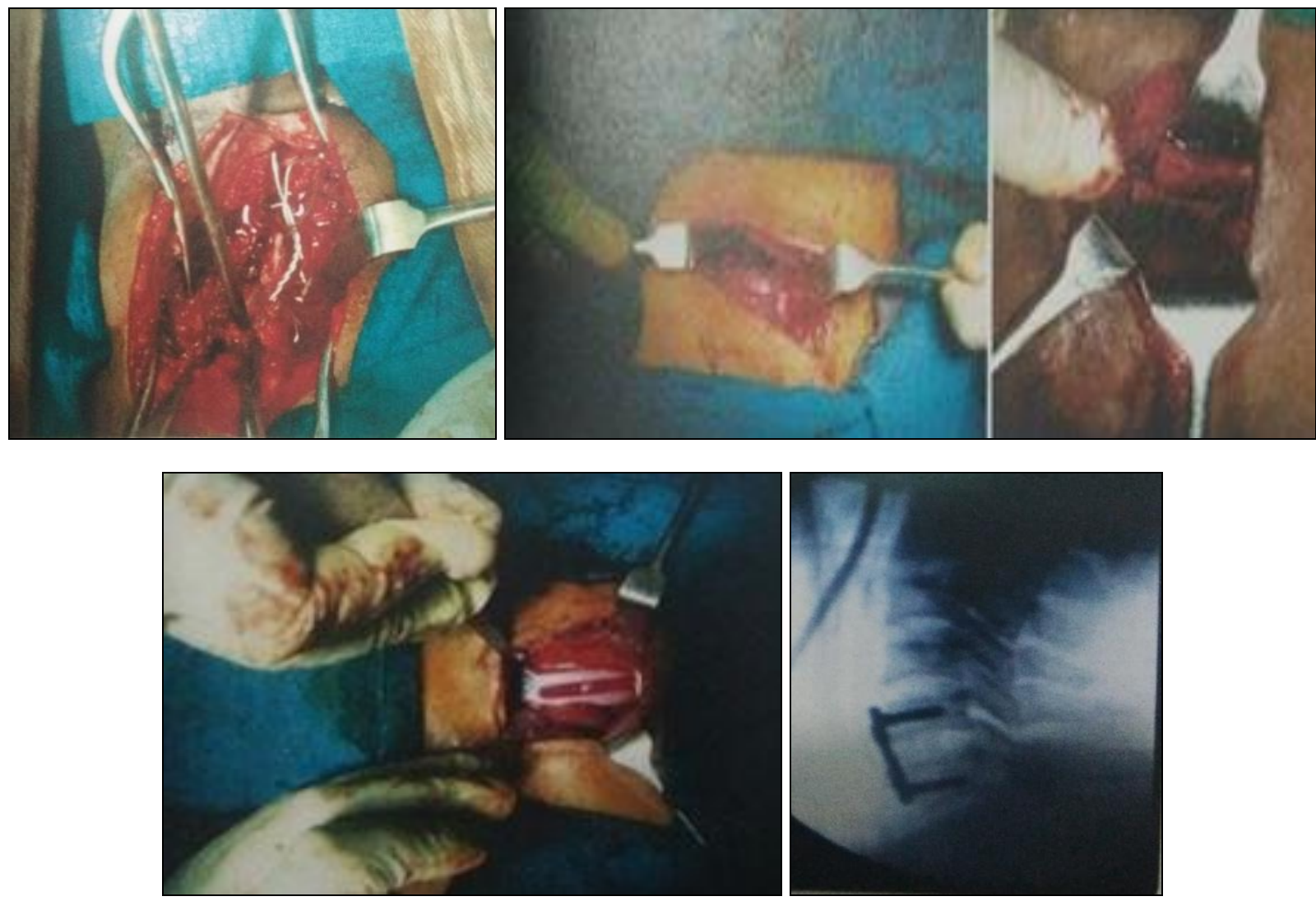

$\sim 592 \sim$ 


\section{Postoperative Protocol}

1. patients were allowed to take liquid diet once the bowel sounds appears

2. post op X-rays were taken

3. IV antibiotics were given for 7 days oral antibiotics were given for 7 days

4. periodic neurological examination were conducted

5. Physiotherapy in the form of active/passive mobilization was continued.

6. Bladder bowel back care was continued.

7. Sutures removed and patients were discharged with collar on 3rd week.

8. the follow up examination and $\mathrm{x}$ rays with the patient reporting at an interval of 6 weeks for first 3 months and thereafter every 3 months. The final year were analysed on the basis of following criteria: neurological recovery as per ASIA scale, bone fusion, stability assessment.

Results

In this study, all the cases are male with most of the patients are in the age group of 41-50 years, Fall from height is the most common of injury followed by road traffic accident, C5C6 \# dislocation is most common spinal injury pattern. Incomplete neurological deficit are more in this study. Most of the cases are flexion distraction type of violence. Most of the cases presented with in one week of injury. Only 4 cases of 40 cases operated by global fusion, both of them are presented late and found to have locked facets. 4 out of 6 cases are expired from complete neurological deficit. Mobilisation of neck started after 6 weeks

\section{Complications}

Totally 6 cases were expired. Two cases was due to acute respiratory distress syndrome. One case due to aspiration pneumonia is. Four patients developed bed sores in which one case developed bed sore preoperatively and other postoperative lay. One patient who had grade 6 sacral sore underwent flap cover with the help of plastic surgeon intervention. Other 6 patients managed conservatively.

\begin{tabular}{|c|c|c|c|c|c|}
\hline Age (years) & No. of patients & percentage & Sex & No. of patients & percentage \\
\hline $11-20$ & 2 & & Male & 40 & 100 \\
\hline $21-30$ & 4 & 10 & Female & 0 & 0 \\
\hline $31-40$ & 8 & 20 & & & \\
\hline $41-50$ & 16 & 40 & & & \\
\hline $51-60$ & 8 & 20 & & & \\
\hline $61-70$ & 2 & 5 & & & \\
\hline
\end{tabular}

\begin{tabular}{|c|c|c|}
\hline Mode of injury & No of patients & percentage \\
\hline Road traffic Accident & 14 & 35 \\
\hline fall from height & 20 & 50 \\
\hline fall with weight on back & 4 & 10 \\
\hline slip and fall on ground level & 2 & 5 \\
\hline
\end{tabular}

\begin{tabular}{|c|c|c|}
\hline Type of injuries & No of patients & percentage \\
\hline C4-C5 fracture dislocation & 6 & 15 \\
\hline C5-C6 fracture dislocation & 14 & 35 \\
\hline C6-C7 fracture dislocation & 12 & 30 \\
\hline C4-C5/C5-C6 traumatic disc prolapse & 2 & 5 \\
\hline C5-C6 subluxation With disc prolapse & 2 & 5 \\
\hline C7 burst fracture & 4 & 10 \\
\hline
\end{tabular}

\begin{tabular}{|c|c|c|}
\hline Classification type & no of patients & Percentage \\
\hline Compressive flexion & 2 & 5 \\
\hline distractive flexion & 32 & 80 \\
\hline vertical compression & 4 & 10 \\
\hline traumatic disc bulge & 3 & 5 \\
\hline
\end{tabular}

\begin{tabular}{|c|c|c|}
\hline Neurological status & no of patients & percentage \\
\hline Complete & 16 & 40 \\
\hline incomplete & 24 & 60 \\
\hline
\end{tabular}

\begin{tabular}{|c|c|}
\hline Time of presentation & no of patients \\
\hline within 24 hours of injury & 12 \\
\hline 1 day To 1 week & 18 \\
\hline 1 week to 1 month & 6 \\
\hline 1 month to 3 month & 4 \\
\hline
\end{tabular}

\begin{tabular}{|c|c|}
\hline Pre op frankels grade & no of patients \\
\hline A & 16 \\
\hline B & 10 \\
\hline C & 12 \\
\hline D & 2 \\
\hline E & 0 \\
\hline Procedure done & no of patients \\
\hline
\end{tabular}

\begin{tabular}{|c|c|}
\hline corpectomy, bone grafting and Plate fixation & 6 \\
\hline $\begin{array}{c}\text { anterior discectomy, bone grafting and plate } \\
\text { fixation plus posterior insterspinous wiring }\end{array}$ & 4 \\
\hline discectomy, bone grafting and plate fixation & 30 \\
\hline
\end{tabular}

\section{Post-operative frankels grade}

\begin{tabular}{|c|c|c|c|c|c|c|}
\hline Pre-operative & \multicolumn{7}{|c|}{ post-operative } & Total \\
\hline & A & B & C & D & E & \\
\hline A & 8 & 6 & 2 & 0 & 0 & 16 \\
\hline B & 0 & 2 & 0 & 4 & 4 & 10 \\
\hline C & 0 & 0 & 0 & 8 & 4 & 12 \\
\hline D & 0 & 0 & 0 & 0 & 2 & 2 \\
\hline E & 0 & 0 & 0 & 0 & 0 & 0 \\
\hline Total & 8 & 8 & 2 & 12 & 10 & 34 \\
\hline
\end{tabular}

Results were analysed during follow up using following criteria

1. Pain

2. Neurological recovery using frankels grade

3. Fusion rate

4. Stability of spine

\section{Discussion}

Spine fractures and spinal cord injury were first reported more than 5000 years ago in the Edwin surgical papyrus. This injury was described as an ailment that should not be treated because of its grave prognosis. Until the first century A.D. therefore, such injuries, primarily the result of direct blows to the spine, were usually managed only with nonoperative, supportive care. The result was usually paralysis and eventual death because there was no way to stabilize the spine and prevent additional damage to the neural elements. ${ }^{[2,3]}$

However, in 600 A.D., Paul of Aegina reported the first spinal laminectomy; he founded that removing spinal lamina splinters from the cord decompressed it, allowing healing. By mid-twentieth century, the perceived mechanism of injury 
began to change from direct blows and sword-induced trauma to high-energy, indirect forces like high-energy motor vehicle and diving accidents, resulting in ligaments and bony injuries. This change in etiology resulted in a change in treatment focus: the philosophy of laminectomy for spinal fractures and cord injury evolved to a philosophy of stabilisation. ${ }^{[2,4]}$

The diagnosis of spinal injury often delayed and the treatment is not uniformly established. The delay in diagnosis may occur because of the lack of obvious deformity on physical or radiographical examination. The most common causes for misdiagnosis are concomitant head injury or alcohol intoxication.

Vacarro et al. formulated a subaxial cervical spine injury classification system [SLIC] in which SLIC score 5 or $>5$ needs operative management. The first recorded operative treatment for spinal injury was laminectomy in the seventh century. Today improved operative techniques have lead to major advances in spinal stabilisation. The development of dedicated spinal cord injury centers and improved postoperative rehabilitation have lead to significant improvement in functional outcome. The treatment of cervical spine fractures and dislocations has several goals, including reduction of the deformity and early rehabilitation. The choice of treatment modality is based on the anatomy of the fractures and the experience of the surgeon. ${ }^{[1]}$

Cervical paling was widely used for stabilisation of sub axial cervical spine injuries. The plate functions as a tension band in extension and as a buttress plate in flexion. After corpectomy for decompression of the spinal canal, the area is filled with a strut graft or a cage, and a plate is used as a loadsharing mechanism. ${ }^{[1,5-8,27]}$.

The role of timing of surgical intervention in spinal cord injury remains one of the most important topic. Despite immense research efforts related to spinal cord injury treatment, neurological recovery and overall outcome remains poor. Research using models has provided evidence that early decompression surgery can lead to improved neurological recovery $[2,9,10]$. In our study, progression of neurological recovery was more in patients underwent early surgical intervention. Hence early surgical intervention still offers hope. ${ }^{[2,11,12,26]}$

In selection of approaches to subaxial cervical spine injuries, the anterior approach directly addresses the injured elements and make easier to proceed with decompression, reduction, grafting and stabilisation. [1, 7] In Case of old neglected subaxial cervical spine injuries, combined approach is preferable, since we can directly encountered the posteriorly locked facets and to remove the excess fibrous tissues around the fracture elements. Studies also supports for global fusion for neglected bifacetal subaxial cervical spine injuries $[13,14$, 29]

Study conducted by lalwani et al. between 2008 to 2011 in the series of 341 cases stated $73 \%$ of patients are between 25 to 64 years of age which was comparable to $80 \%$ of patients in our study. Between 2001 to 2004 study conducted by Shrestha et al. showed $60 \%$ of cases are due to fall from height in a series of 149 patients with cervical spine injuries, which was comparable to $50 \%$ of patients in our study, since fall from height and carrying weight is due to occupational trend in our country like agricultural and labour work. ${ }^{[15,16]}$.

It was generally accepted that the most injured spinal level is at $5^{\text {th }}$ and 6 th cervical vertebra, as this level has greatest range of flexion or extension stress and therefore most susceptible to trauma. Zubia et al. showed $31 \%$ nof patients with cervical spine injuries, the commonest level being c5-c6, in a series of
214 patients, conducted between 2003 to 2007, which was similar to our study shows $35 \%$. ${ }^{[17]}$.

In our study, most common level of injury was c5-c6 fracture dislocation $(35 \%)$ followed by c6-c7 level, which was comparable to $31 \%$ noted in earlier studies. It was generally accepted that the most injured spinal level is at $5^{\text {th }}$ and 6th cervical vertebra, as this level has greatest range of flexion or extension stress and is therefore most susceptible to trauma. $[17,18]$

Flexion-distraction type of violence was more in the study, these injuries can in facet sprains, facet dislocations, jumped facet or perched facets. We observed that $80 \%$ of the cases are involved with flexion distractive type of violence which was more when compared to previous studies showed $61 \% .{ }^{[19,25]}$. In our study, $60 \%$ of patientswre incomplete neurological deficit and $40 \%$ of patients are complete neurological deficit as per ASIA impairment scale, which was comparable to $59.5 \%$ complete neurological picture as quoted in earlier studies. Totally 6 patients was expired in which 4 patients were complete neurological deficit. Ducker et al. reported $34 \%$ of mortality at the end of 1 year in their series of 273 patients with complete cord injuries, which was more when comparable to our study $25 \%$. (4 out if 16 patients with complete neurological deficit). ${ }^{[20,21,24,28]}$.

Pressure sore one of the known complication of cervical spine injuries. In our study, 8 patients had sacral pressure sore, 6 patients treated conservatively. Two patient underwent flap cover with the help of plastic surgery intervention. Stal et al. cited a $20 \%$ incidence in paraplegic patients and a $26 \%$ incidence on patients who are quadriplegic, which was comparable to $20 \%$ in our series. ${ }^{21,22]}$.

Paramore et al. reported hardware failure in $22 \%$ patients and concluded that plate length correlates with instrumentation problems. While in our study, there was no complications related to plating like screw pullout and implant failure. The normal lordotic curve of cervical spine is maintained in all cases

Patients were classified onto five grades as per ASIA impairment scale.In grade A out of 16 patients, 8patients had no improvement, 6 patients gained some sensory improvements of which two patients died after two months due to aspiration pneumonitis, and 2 patients improved to grade c.in grade $\mathrm{B}$, out of 10 patients, 4 patients improved to grade $\mathrm{D}, 4$ patients improved to grade $\mathrm{E}$ and two patients died on immediate post-operative period. In grade C, out of 12 patients, 8 patients improved to grade $\mathrm{D}, 4$ patients improved to grade E. two patient in grade D improved to grade $\mathrm{E}$ after surgical intervention. We had no patients on grade E. In our study, patients improved to grade 2 more power after early surgical stabilisation and no patients underwent neurological deterioration.

\section{Conclusion}

The ultimate goal of surgical intervention for sub axial cervical spine injuries is stabilization of spine, restoration of spinal anatomy, decompression of neural elements, thereby promoting the neurological recovery and early facilitation of rehabilitation. In our study, we achieved a good functional outcome following surgical intervention. To conclude that early surgical stabilization of sub axial cervical spine injuries has good functional outcome, provided detailed clinical and radiological assessment, proper preoperative planning, selection of surgical approaches, precision in surgical techniques and early rehabilitation program are needed in achieving good results and minimising complications. 


\section{References}

1. The surgical approach to subaxial cervical spine injuries. An evidence based on the SLIC classification system, marcel F. Dvorak, MD, FRCSC, Charles G. Fisher, MD, MHSc, FRCSC, SPINE, 32(23), 2620-2629.

2. Frymoyer adult and paediatric spine surgery $2^{\text {nd }}$ edition chapter, 34

3. Garfin SR, Blair B, Eismont FJ. skeletal trauma; fractures, dislocations, ligamentous injuries $2^{\text {nd }}$ edition Philadelphia: WB Saunders, 1998, 947-1034

4. Fife D, Kraus J. Anatomic location of spinal cord injury. Relationship t cause of injury. Spine. 1986; 11(1):2-5.

5. De oliveira JC. Anterior plate fixation of traumatic lesions of the lower cervical spine spine. 1987; 12:32429.

6. Aebi M, Zuber K, Marchesi D. treatment of cervical spine injuries with anterior plating. Indications, techniques, and results. Spine. 1991; 16:38-45.

7. Grubb MR, Currier BL, Shih JS, Bonin V, Grabowski JJ, Chao EY. Biomechanical evaluation of anterior cervical spine stabilisation. Spine 1998; 23:886-92.

8. Thalgott JS, Xiongsheng C, Giuffre JM. Single stage anterior cervical reconstruction with titanium mesh cages, local bone graft, and anterior plating: spine J. 2003; 3:294-300.

9. Bohlman HH. Acute fractures and dislocations of the cervical spine. An analysis of three hundred hospitalized patients and review of literature. $\mathrm{J}$ bone joint surg Am. 1979; 61(8):1119-42.

10. Paul J, Schenarts MD, Jose Diuaz MD, Clay Kaiser. Prospective comparison of admission computed tomographic scan and plain films of the upper cervical spine in trauma patients with altered mental status, J Trauma. 2001; 51:663-669.

11. Neurologic outcome of early versus late surgery for cervical spinal cord injury vaccaro, Alexander R.MD; Daugherty, Reza J.BA; Sheehan, Terrence P MD. Dante, Stephen J.MD; spine issue: volume 22(22), 15 November 1997, 2609-2613.

12. Subaxial (C3-C4) cervical spine injuries: comparison of early and late surgical intervention vashdev chandwani MS, BK Ojha M Ch, anil Chandra MCh, mohammad kaif MS, Vishwanath GU MS, Department of neurosurgery, CSMMU (upgraded king George's Medical University), Lucknow. Indian journal of neurotrauma (IJNT). 2010; 7(2):145-148

13. Circumferential fusion for subaxial cervical spine fracture-subluxations TS Vsana MCh Department of neurosurgery command hospital (EC), Kolkata (WB) Indian journal of neurotrauma. 2007; 4(1):65-70.

14. Management of neglected cervical spine dislocation: A study of six cases Vijay Goni, Nirmal Raj Gopinathan, Vibhu Krishnan, Rajesh kumar, Avinash Kumar, Chinese journal of traumatology. 2013; 16(4):212-215.

15. Mortality profile of patients with traumatic spinal injuries at a level 1 trauma care centre in India S. Lalwani, V. Singh, V. Trikha, V. Sharma, S. Kumar, R. Bagla, D. Aggarwal and M. S. Misa, Deparrtment of forensic medicine and toxicology, orthopaedics, neurosurgery and surgical disciplines, Jai Prakash Narayan Apex Trauma Center, All India institute of medical sciences, New Delhi, India. Indian J Med Res. 2014; 140:40-45.

16. Cervical spine injuries in Nepal, a clinic epidemiological study Shreshtha D, Carg M, Department of orthopaedics,
B P Koirala institute of health sciences, dharan, Nepal. J Nepal Med Assoc. 2007; 46(167):107-111.

17. Traumatic cervical spine injury pattern-a snapshot Joshi M.1, Agrawal Mahima2, IJPMR September. 2012; 23(3):111-6.

18. Solagberu BA. Spinal cord injuries in Ilorin Nigeria. West Afr J Med. 2002; 21:230-2

19. Flexion-distractioninjuries of the subaxial cervical spine, Kris Radcliff, MD, a, b, and Benjamin G. Thomasson, Doc a Department of orthopaedic surgery, Rothman institute, Thomas Jefferson University. Philadelphia, PA, seminars in spine surgery. 2015; 25:45-56.

20. Factors affecting long term outcome in acuter cervical cord injury KVL Narasinga Rao M Ch, M Vijaya Saradhi M Ch, AK Purohit MCh Department of neurosurgery, Nizam's institute of medical sciences, Hyderabad. Indian journal of neurotrauma. 2010; 7(2):149-156.

21. Burns SP, Golding DG, Rolle WA Jr, Graziani V, Ditunno JF Jr. Recovery of ambulationin motor incomplete tetraplegia. Arch Phys Med Rehabil. 1997; 78:1169-72.

22. Stal S, Serure A, Donovan W. the perioperative managementof the patient with pressure sores. Ann plast surg. 1983; 11:347.

23. Pressure sores. Chapter 74, john d, bauer, john s. Mancoll, and linda g. Phillips.

24. Neurological recovery after surgical interventionin lower cervical spine injuries, Moslem shakeri medwell surgery journal, 2008, 58-60,

25. Treatment of subaxial cervical spinal injuries journal of neurosurgery, neurosurgery. 2013; 72:187-197.

26. The functional and neurological outcome in cervical spine injuries: a retrospective review. The internet journal of orthopaedic surgery, 2009, 17(1).

27. Anterior decompression, fusion and plating in cervical spine injury: early experience in Abuja, Nigeriasurgical neurology international, published: November, 11, 14.

28. Evaluation of morbidity, mortality and outcome following cervical spine injuries in elderly patients Eur spine J, 2008; 17:586-591.

29. Delayed presentation of cervical facet dislocations Saumyajit Basu, Farid H Malik, Jay Deep Ghosh, Agnivesh Tikoo Department of neurosciences, Park Clinic, Minto Park, Kolkata, India. Journal of orthopaedic surgery. 2011; 19(3):331-5. 